theory. The results obtained by the finite element method indicate that the critical slip surface moves towards the slope surface and develops downwards. However, there is still a lack of a detailed study to investigate the important parameters that have an influence on the ultimate limit state and serviceability limit state of the excavation and slope system.

In this study, the global factor of safety FS obtained via the shear strength reduction (SSR) technique (also called $c-\varphi$ reduction method) is used as the criterion to determine the ultimate limit state and the calculated maximum lateral wall deflection is adopted as the serviceability limit state criterion. A detailed study was carried out to evaluate the influence of the excavation geometry, the supporting system stiffness, and the distance between the braced excavation and the existing slope on the excavation-slope system response using the finite element program PLAXIS2D [1]. Based on these results, response surface models were developed for the ultimate and serviceability limit states. Subsequently, the First-Order Reliability Method (FORM) is adapted to perform probabilistic analysis on the global factor of safety through setting the threshold maximum wall deflection as an optimization constraint to enable a rational design approach for deep braced excavations adjacent to slopes in mountainous terrain.

\section{Finite element analysis}

\subsection{Numerical modeling}

The Plaxis2D software was utilized for the numerical simulations. The Mohr-Coulomb constitutive model was selected for the soil. A typical cross-section of the excavation and slope system, as well as the properties of the soil and the supporting elements are shown in Fig. 1. It should be noted that the adopted soil properties are typical of the ground conditions in Chongqing and that the soil and wall profiles, the excavation geometries as well as

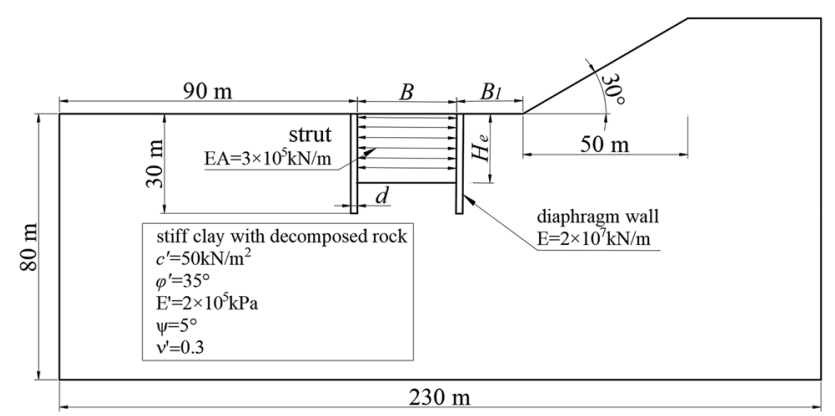

Fig. 1 Cross-sectional soil and wall profile the boundary conditions are simplified from a deep braced project in Chongqing.

The analyses considered a plane strain excavation near an unreinforced slope supported by a retaining wall system and a total of 6 levels of struts located below the original ground surface at depths of $-1 m,-4 m,-7 m$, $-10 m,-13 m$ and $-16 m$, respectively. The soil was modeled by 15 -noded triangular elements, following the Mohr-Coulomb failure criterion. The structural elements were assumed to be linear elastic in Plaxis2D, the struts and the wall is represented by 3-noded bar elements and 5 -noded beam elements, respectively.

The soil properties are regarded as deterministic and presented in Fig. 1. This study mainly examines the influences of the retaining wall system stiffness and the excavation geometries on the responses including the global factor of safety of the braced excavation-upper slope system, as well as the retaining wall deflection. The ranges of these key design parameters are listed in Table 1. It should be explained that $\ln (S)$ represents the natural logarithm of the system stiffness, e.g., $\ln \left(E I / \gamma_{w} h_{a r g}^{4}\right.$ The three values of 3.794, $4.605,5.187$ are realised by changing the corresponding wall thickness of $0.6,0.9$ and $1.2 \mathrm{~m}$ with average vertical strut spacing $h_{\text {avg }}=3 \mathrm{~m}, \gamma_{w}=10 \mathrm{kN} / \mathrm{m}^{3}$ and keeping the Young's modulus of the wall constant $\left(E=2.1 \times 10^{7} \mathrm{kN} / \mathrm{m}^{2}\right)$.

According to Poh and Wong [22], the strut stiffness does not have a very significant influence on wall deflection when the strut is stiff. A constant strut stiffness EA of $3.0 \times 10^{5} \mathrm{kN} / \mathrm{m}$ is assumed. Based on Table 1 , more than 160 hypothetical cases were analysed.

The construction assumption and sequence are as follows:

1. The wall is installed without any disturbance (wished into place);

2. The soil is excavated prior to installing the strut, uniformly $1 \mathrm{~m}$ below each strut level until the final depth $\mathrm{H}_{e}$ is reached.

3. Each phase of strut installation is followed by a subsequent phase in which the global safety factor is determined by the SSR method proposed by Zienkiewicz et al. [35], and improved by Brinkgreve and Bakker [2].

Table 1 Parameters considered and the ranges to be examined

\begin{tabular}{ll}
\hline Parameters & Ranges \\
\hline System stiffness in logarithmic scale $\ln (S)$ & $3.794,4.605,5.187$ \\
Excavation width $B(\mathrm{~m})$ & $20,30,40$ \\
Excavation depth $H_{e}(\mathrm{~m})$ & $14,17,20$ \\
Wall thickness $d(\mathrm{~m})$ & $0.6,0.9,1.2$ \\
Distance between wall and toe of slope $B_{1}(\mathrm{~m})$ & $5,10,15,20,30,40$ \\
Wall penetration ratio $D / H_{e}$ & $0.50,0.76,1.14$ \\
\hline
\end{tabular}


The procedure of the SSR method involves systematically reducing the soil shear strength until failure occurs. It has been verified by Lian et al. [16] that the SSR FE method can be widely applied in the engineering practice. In addition, Cheng et al.[4], Goh and Zhang [9], Ishii et al. [12], Zhang and Goh [30], Tschuchnigg et al. [24], Oberhollenzer et al. [21], Gao et al. [6], Schneider-Muntau et al. [23], Dyson and Tolooiyan [5] have also demonstrated that the SSR technique performs well in the many slope cases analysed.

The detailed construction sequence is listed in Table 2.

\subsection{Numerical results and analysis}

The numerical results include the global factor of safety FS obtained via SSR and the maximum lateral wall deflection $\delta_{h m}$.

\subsubsection{Factor of safety}

Figure 2 plots the variation of incremental displacement contours, as excavation proceeds, for cases with $B=30 \mathrm{~m}$, $B_{1}=5 \mathrm{~m}, \ln (S)=4.605$. The corresponding $F S$ values for excavation depths $H_{e}$ of $0,14,17,21 \mathrm{~m}$ are also shown. It can be observed that as the excavation depth $H_{e}$ increases, the zone showing the incremental displacement (in red) enlarges and the corresponding FS values decrease. A comparison shows that after the final stage of excavation, the FS is about 1.705 , which is a decrease of 0.636 from the original FS of 2.341 (prior to any excavation). The results indicate that excavations close to an existing slope may result in a significant reduction of the FS of the slope, which may cause slope instability or even failure.

Figure 3 presents some typical plots of the decrease of the factor of safety values $\Delta \mathrm{FS}$ with increasing distance between the wall and the toe of the slope $B_{1}$ for three different excavation widths $B$ with $H_{e}=20 \mathrm{~m}$ and $S=4.605$. As expected, $\triangle \mathrm{FS}$ decreases with increasing distance between the wall and the existing slope $B_{1}$. The $\Delta \mathrm{FS}$ was also influenced by the width of the excavation $B$. The $\triangle F S$ was minimal for $B_{1}=20 \mathrm{~m}$ when $B=20 \mathrm{~m}$. For the larger $B$ values of $30 \mathrm{~m}$ and $40 \mathrm{~m}, \Delta \mathrm{FS}$ was minimal at a greater distance of $\mathrm{B}_{1}=40 \mathrm{~m}$.

\subsubsection{Wall responses}

Figures 4 and 5 show the variation of the wall lateral deformation profiles and the bending moments of the right wall (near the slope) for cases with different $B_{1}$, respectively. The final excavation depth $\left(H_{e}\right)$ is $20 \mathrm{~m}$ and supported by $1.2 \mathrm{~m}$-thickness and $30 \mathrm{~m}$-deep diaphragm wall with 6 levels of struts for $B_{1}$ ranging from 5 to $40 \mathrm{~m}$, respectively. All the plots show a concave wall deflection shape.
Table 2 Detailed construction procedures

\begin{tabular}{ll}
\hline Phases & Construction procedures \\
\hline Initial phase & Generate the soil initial effective stress and pore water pressure \\
Phase 1 & Determine the initial global safety factor by SSR method \\
Phase 2 & Install the diaphragm wall \\
Phase 3 & Excavate to $2 \mathrm{~m}$ below the ground surface inside the excava- \\
& tion, install the first level strut \\
Phase 4 & Excavate to $5 \mathrm{~m}$ below the ground surface \\
Phase 5 & Install the second level strut \\
Phase 6 & Calculated the global safety factor by SSR method \\
Phase 7 & Excavate to $8 \mathrm{~m}$ below the ground surface \\
Phase 8 & Install the third level strut \\
Phase 9 & Calculated the global safety factor by SSR method \\
Phase 10 & Excavate to $11 \mathrm{~m}$ below the ground surface \\
Phase 11 & Install the fourth level strut \\
Phase 12 & Calculated the global safety factor by SSR method \\
Phase 13 & Excavate to $14 \mathrm{~m}$ below the ground surface \\
Phase 14 & Install the fifth level strut at \\
Phase 15 & Calculated the global safety factor by SSR method \\
Phase 16 & Excavate to $17 \mathrm{~m}$ below the ground surface \\
Phase 17 & Install the sixth level strut \\
Phase 18 & Calculated the global safety factor by SSR method \\
Phase 19 & Excavate to $20 \mathrm{~m}$ below the ground surface \\
Phase 20 & Calculated the global safety factor by SSR method \\
\hline
\end{tabular}


Fig. 2 Contour of slip surface and $F S$ for different excavation depths $H_{e}$ for $B=30 \mathrm{~m}, B_{1}=5 \mathrm{~m}$, $S=4.605$

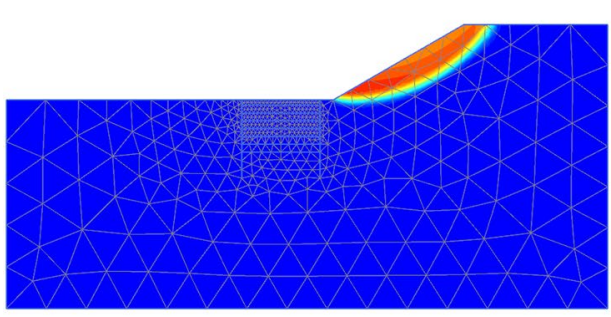

(a) $H_{e}=0 \mathrm{~m} \quad F S=2.341$

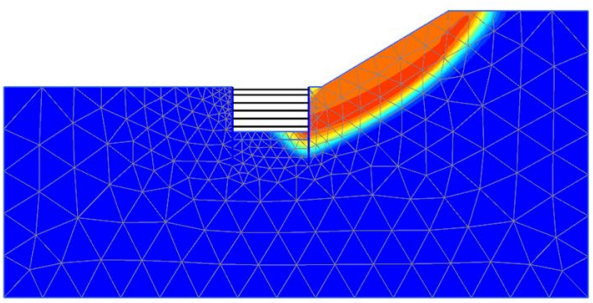

(c) $H_{e}=17 \mathrm{~m} \quad F S=2.095$

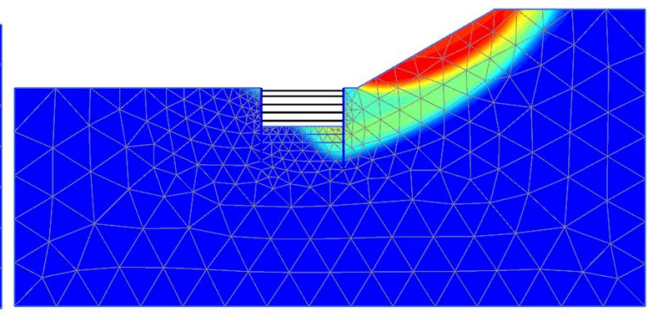

(b) $H_{e}=14 \mathrm{~m} F S=2.214$

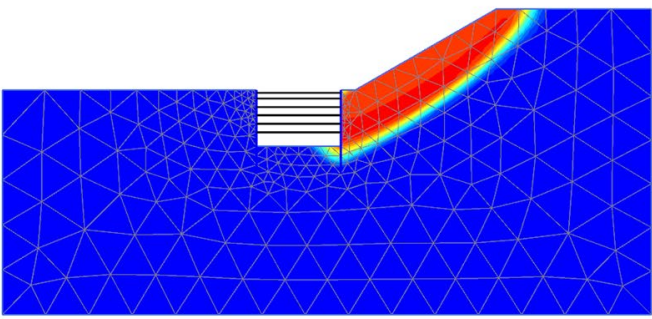

(d) $H_{e}=20 \mathrm{~m} F S=1.705$

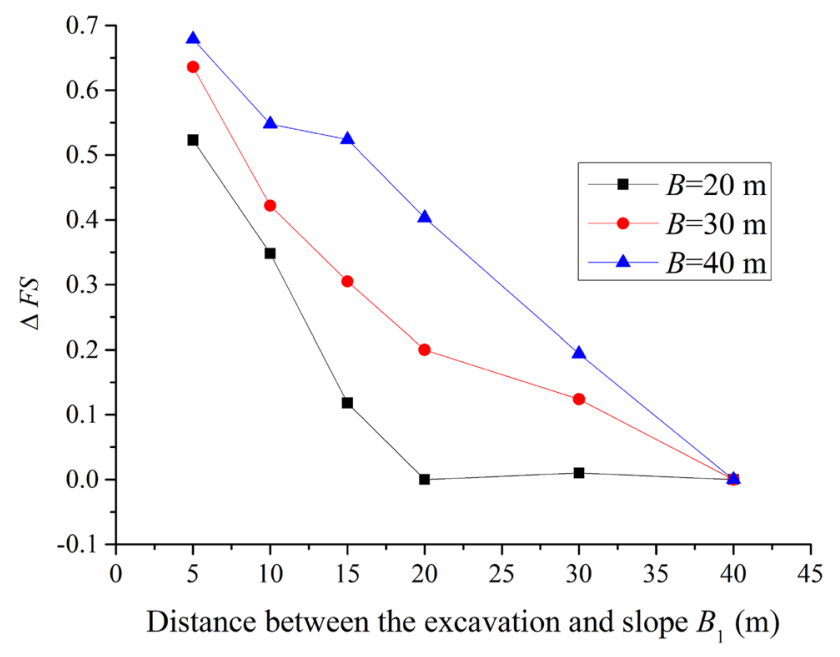

Fig. 3 Decrease of the factor of safety $\triangle F S$ for different $B_{1}$ with $H_{e}=20 \mathrm{~m}, \mathrm{~S}=4.605$

As shown in Fig. 4, the maximum wall lateral deformation decreases as $B_{1}$ increases. As $B_{1}$ increased from 5 to $40 \mathrm{~m}$, the maximum wall lateral deformation decreased by $30 \%$. As shown in Fig. 5, the maximum bending moment occurs below the final excavation level (FEL). The change in the maximum bending moments is not as significant with a reduction of only $18 \%$ when $B_{1}$ increased from 5 to $40 \mathrm{~m}$.

Figure 6 shows the plot of the maximum lateral wall deflection $\delta_{h m}$ for different $B$ and $B_{1}$ with $H_{e}=20 \mathrm{~m}$, $S=4.605$. The trends are similar to that observed for $\Delta \mathrm{FS}$ in Fig. 3 , i.e., $\delta_{h m}$ decreases as the excavation width $B$ decreases and the distance between the wall and the toe of the slope $B_{1}$ increases. The influence of excavation width $B$ on $\delta_{h m}$ is more significant when $B_{1}$ is smaller, i.e.,

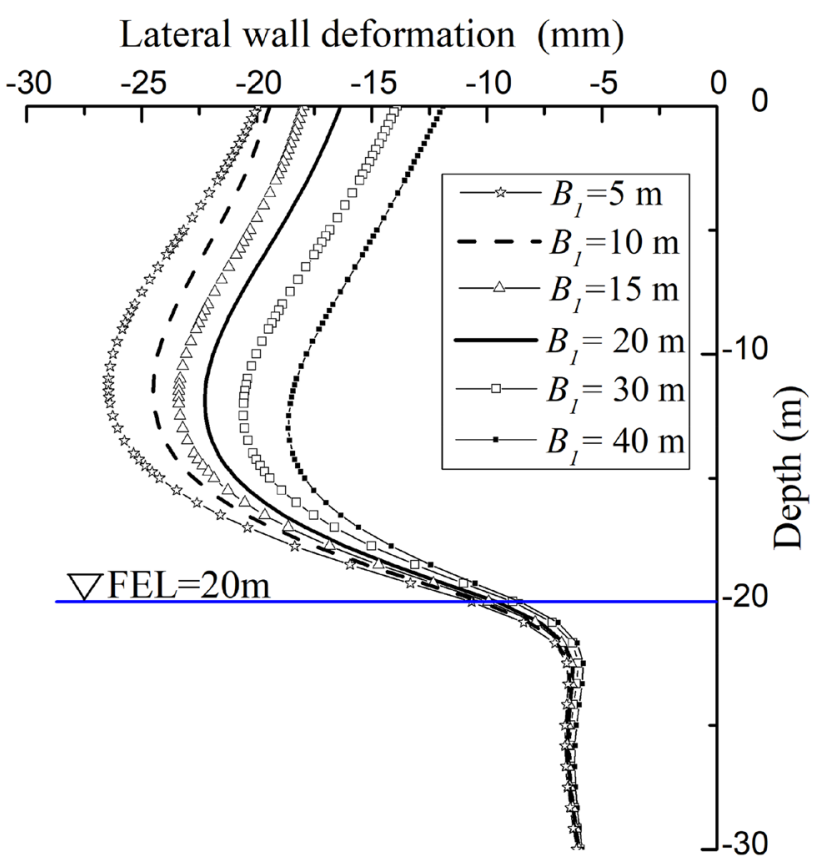

Fig. 4 Lateral deformation of the wall for different $B_{1}$

the slope toe is closer to excavation. For example, the difference $\Delta \delta_{h m}$ between $B=40 \mathrm{~m}$ and $B=20 \mathrm{~m}$ is $7.5 \mathrm{~mm}$ at $B_{1}=5 \mathrm{~m}$. It decreases to $3.2 \mathrm{~mm}$ at $B_{1}=10 \mathrm{~m}$.

\section{Surrogate models for limit state functions}

In order to assess the performance in deep braced excavations adjacent to an existing slope, both the ultimate limit state (ULS) and the serviceability limit state (SLS) of the 


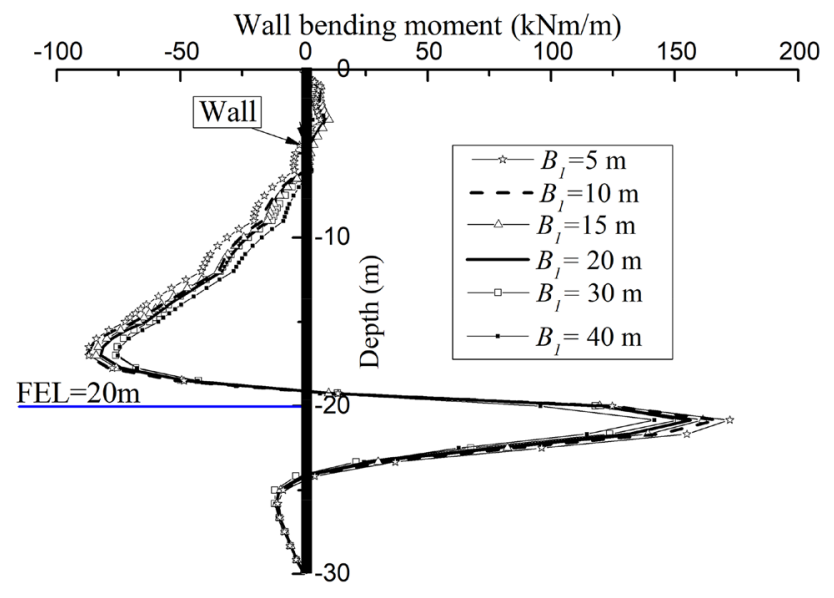

Fig. 5 Wall Bending moments for different $B_{1}(\mathrm{~mm})$

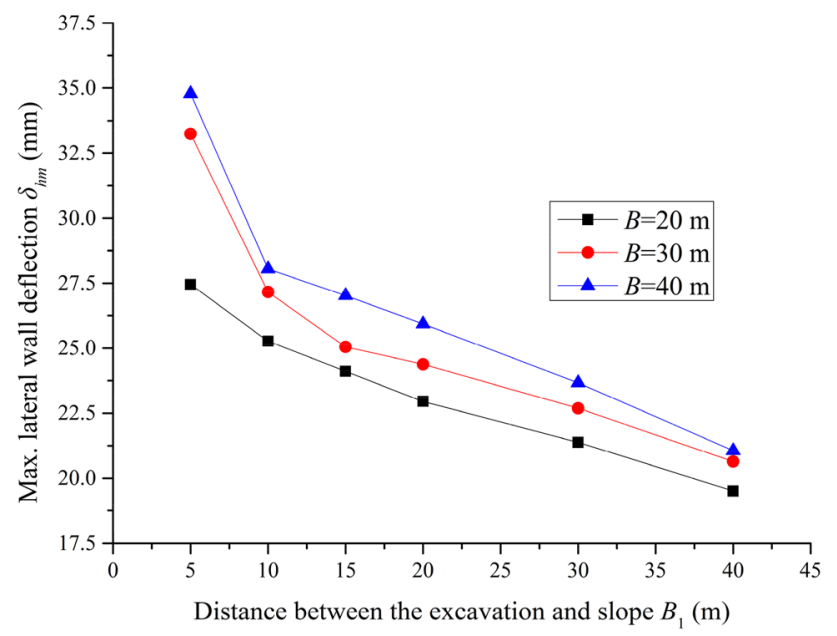

Fig. 6 Max. lateral wall deflection $\delta_{h m}$ for different $B_{1}$ with $H_{e}=20 \mathrm{~m}, \mathrm{~S}=4.605$

excavation-slope system should be satisfied. In the following subsections, the limit state functions for ULS and SLS are developed respectively, based on the numerical results presented in the previous section.

\subsection{Ultimate limit state surrogate model}

Based on the calculated FS results, a Polynomial Regression (PR) model has been developed for estimating the global factor of safety $F S$ as a function of four input parameters $B, B_{1}, H_{e}$ and $S$, with a coefficient of determination $\mathrm{R}^{2}$ of 0.881 . The expression is shown in Eq. (1):

$$
\begin{aligned}
F S_{-P R}= & 7.35 \times 10^{-2} B-1.57 \times 10^{-1} B_{1}+3.51 \times 10^{-2} H_{e} \\
& +1.02 S-2.5 \times 10^{-6} B^{2}-2.29 \times 10^{-4} B_{1}^{2} \\
& -8.07 \times 10^{-4} H_{e}^{2}-2.22 \times 10^{-2} S^{2}+2.4 \times 10^{-4} B B_{1} \\
& -4.08 \times 10^{-3} B H_{e}+1.65 \times 10^{-4} B S+8.01 \times 10^{-3} H_{e} B_{1} \\
& -1.56 \times 10^{-3} S B_{1}-2.8 \times 10^{-2} H_{e} S-1.84 \times 10^{-2} B\left(D / H_{e}\right) \\
& +4.83 \times 10^{-2} B_{1}\left(D / H_{e}\right)+9.4 \times 10^{-2} H_{e}\left(D / H_{e}\right) \\
& -3.55 \times 10^{-1} S\left(D / H_{e}\right)
\end{aligned}
$$

Figure 7 plots the factor of safety values determined from the finite element analyses FS $-F E M$ against the calculated $F S_{-P R}$ results based on Eq. (1). Also shown in the plot are the $100 \%$ agreement line and the $10 \%$ error lines. The results indicate that Eq. (1) is fairly accurate in predicting the global factor of safety for deep braced excavations adjacent to slopes.

\subsection{Serviceability limit state surrogate model}

Similarly, a Logarithmic Regression (LR) model was developed for predicting the maximum lateral wall deflection $\delta_{h m}$, with a fairly high coefficient of determination $\mathrm{R}^{2}=0.946$. The expression is shown in Eq. (2):

$\delta_{h m_{-} L R}=0.1133 B^{0.1086} B_{1}^{-0.223}\left(H_{e}\right)^{2.1247}\left(D / H_{e}\right)^{0.0568} S^{-0.4448}$

Figure 8 plots the estimated maximum lateral wall deflections $\delta_{h m_{L} L R}$ values against the finite element calculated results $\delta_{\text {hm_FEM }}$. Also shown in the plot are the $100 \%$ agreement line and the $20 \%$ error lines, indicating that Eq. (2) is fairly accurate in predicting the maximum

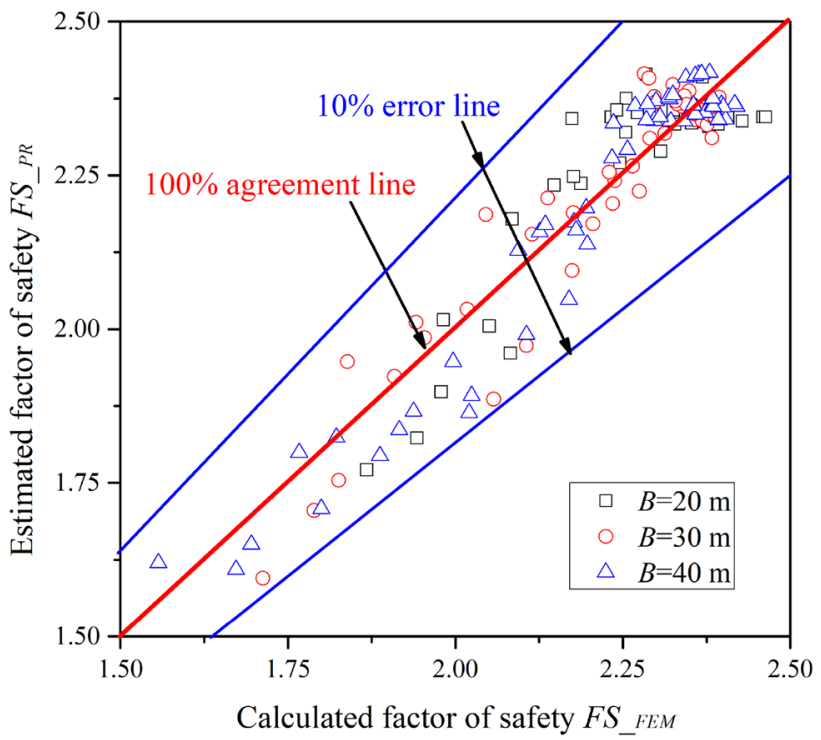

Fig. 7 Comparison between FS_FEM and FS_PR 


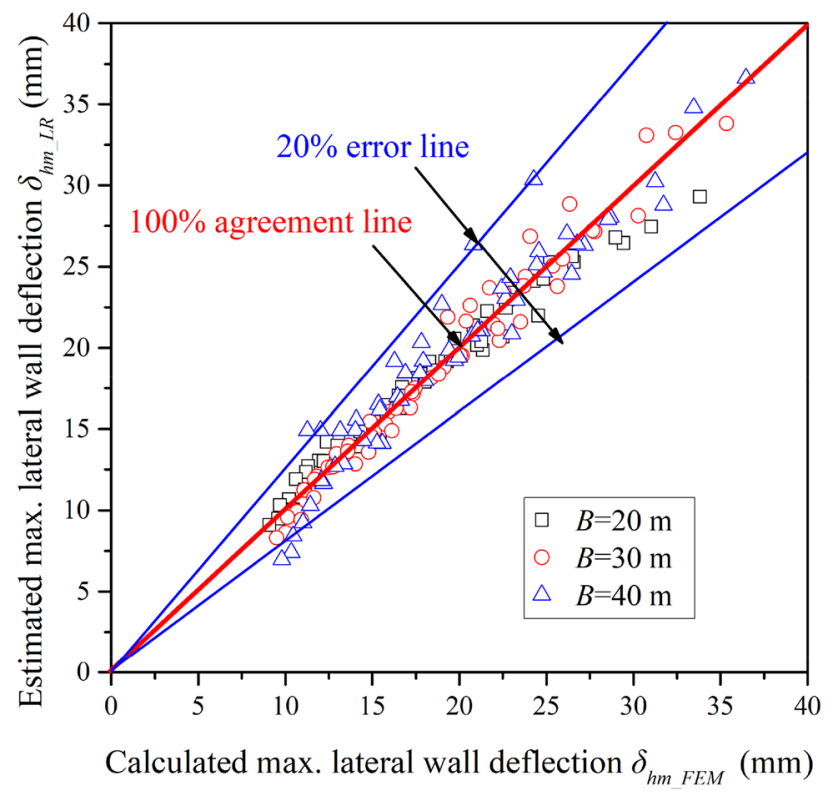

Fig. 8 Comparison between $\delta_{h m_{-} F E M}$ and $\delta_{h m_{-} L R}$

wall deflections for deep braced excavations adjacent to slopes.

\section{Probabilistic assessment of the limit state functions}

The First-Order Reliability Method (FORM) [11] is adopted in this study for probabilistic assessment of the two limit state functions. It can deal with the unknown PDFs of the random variables in most geotechnical applications and the demanding of computation of integration when multi-variables are involved. FORM has been proved that the Microsoft EXCEL spreadsheet can be used to perform the minimization and determine reliability index $\beta[14,18$, $29,34,36]$.

The reliability index $\beta$ and the probability of failure $P_{f}$ for both the ultimate and the serviceability limit states can be performed using FORM based on the built PR and LR models presented in the previous section. Based on the approach by Low and Tang [18], the ULS model expressed as Eq. (1) has been incorporated into an EXCEL spreadsheet environment, from which the reliability index $\beta$ can be determined. A sample spreadsheet for computing the factor of safety $F S$ is shown in $0 a$, in which the values of the input random variables are the same as those used in the simulation model. According to Low and Tang [18], the spreadsheet cells B3: B5 allows the random variables distribution has the selection of various types including lognormal, normal, triangular etc. Cells D3: E5 are average values and standard deviation which are set corresponding to the random variables in Cells B3: B5, three random variables are of the normal distribution. Cells $\mathrm{G} 3: 15$ represent the correlation matrix $\mathbf{R}$ used to define the correlations between $B, H_{e}$ and S. Cells J3: J5 denote the $n_{i}$ vector which contains equations for $\left(x_{i}-u_{i}^{N}\right) / \sigma_{i}^{N}$. The $x_{i}^{*}$ values were firstly set equal to the mean values $(30,17,4.5)$ of the original random variables $\left(B, H_{e^{\prime}} S\right)$. Then by invoking the spreadsheet's built-in optimization routine SOLVER to search algorithm by minimize the cell $L 3$, through changing the $\mathbf{n}_{\mathbf{i}}$ values subject to $G(x)=0$, the design point $\left(\mathbf{x}_{\mathbf{i}}^{*}\right.$ values) can be obtained. It should be stressed that in the spreadsheet environment, iterative numerical derivatives and directional search for the design point $\mathbf{x}_{\mathbf{i}}^{*}$ were automatically carried out via SOLVER search. The probabilistic assessment of SLS in Fig. 9. is almost identical to 0except for the $G(x)$ formulations. For the detailed procedures in performing the FORM spreadsheet framework to derive $\beta$ and the corresponding $P_{f}$, please refer to Zhang and Goh [29].

\subsection{Probabilistic assessment of the ultimate limit state}

For either the braced excavation or the slope, design codes or guidelines specify the minimum factor of safety. For example, in Chongqing (China) the building authorities specify a minimum factor of safety of 1.30 for slopes in mountainous terrains. However, for the braced excavationupper slope system, there are no guidelines or codes with regards to the critical safety factor values. Thus, the influence of the critical factor of safety FS_cr on the reliability index $\beta$ and the probability of failure $P_{f}$ of the ultimate limit state ULS of the braced excavation-upper slope system is examined in this study, which can justify the choice of certain threshold factor of safety.

Figure 10 plots the influence of the various design parameters on the reliability index $\beta$ and the probability of failure $P_{f}$ of the ULS. Both the coefficient of variation of the system stiffness $\mathrm{COV}_{S}$ and the critical factor of safety FS_cr has significantly influence on the $\beta$ and $P_{f}$. A larger COV results in a smaller $\beta$. However, there is less significant difference on $\beta$ and $P_{f}$ between $\mathrm{COV}_{S}=0.05$ and $\mathrm{COV}_{S}=0.1$. In addition, the reliability index $\beta$ decreases with $F S_{-} C r$ and converged at $F S_{-} c r=2.2$, similarly $P_{f}$ increases with $F S_{-} c r$ and converged at $F S_{-} C r=1.6$.

Figure 11 compares the influence of both the $\mathrm{COV}_{S}$ and $B_{1}$ on $P_{f}$ for $B=20,30,40 \mathrm{~m}$, respectively, for $H_{e}=17 \mathrm{~m}$, $S=4.5$, and assuming the critical factor of safety $F S_{-} \mathrm{cr}=2.0$. It is obvious that $P_{f}$ decreases with the increase of $B_{1}$ while $P_{f}$ increases with the increase of excavation width $B$. A larger $\mathrm{COV}_{S}$ results in a larger $P_{f}$. However, there is no difference on $P_{f}$ between $\operatorname{COV}_{S}=0.05$ and $\operatorname{COV}_{S}=0.1$. the $P_{f}$ decreases with $B_{1}$ and converged at $B_{1}=15 \mathrm{~m}$ when 


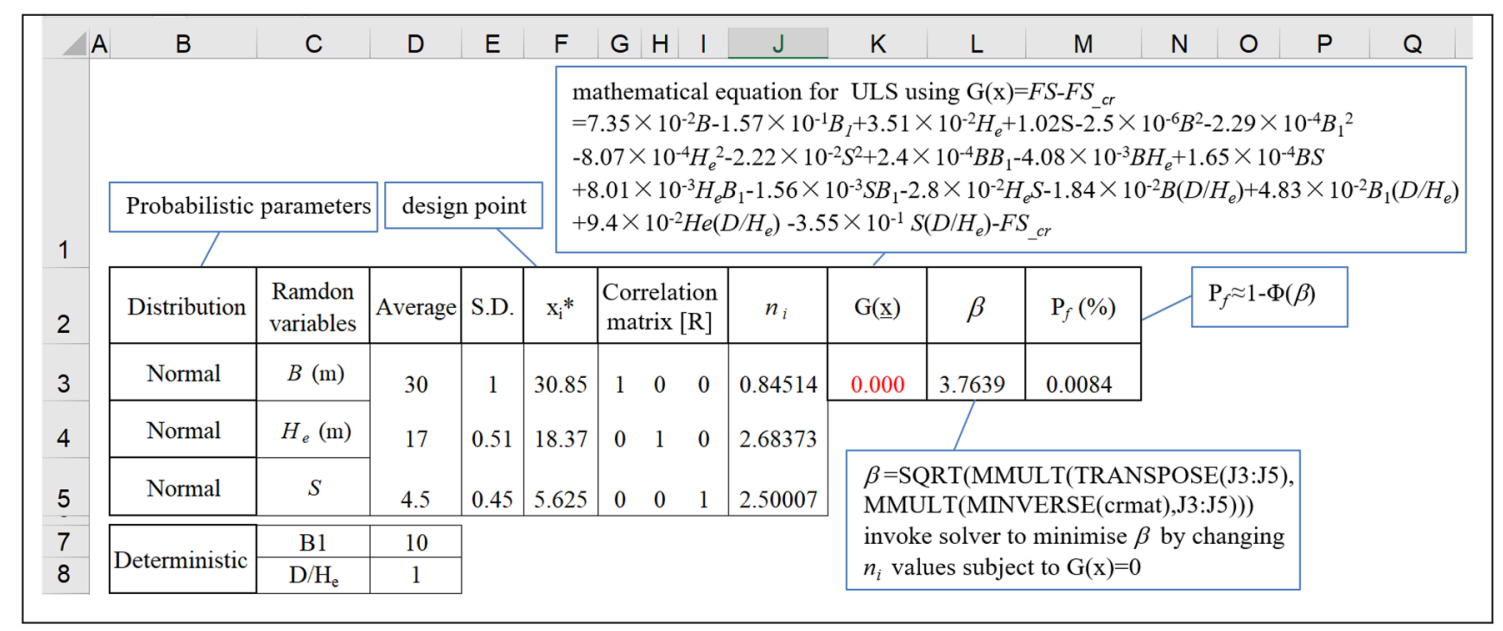

(a) Calculation on $\beta$ and $P_{f}$ for the ultimate limit state using FORM spreadsheet

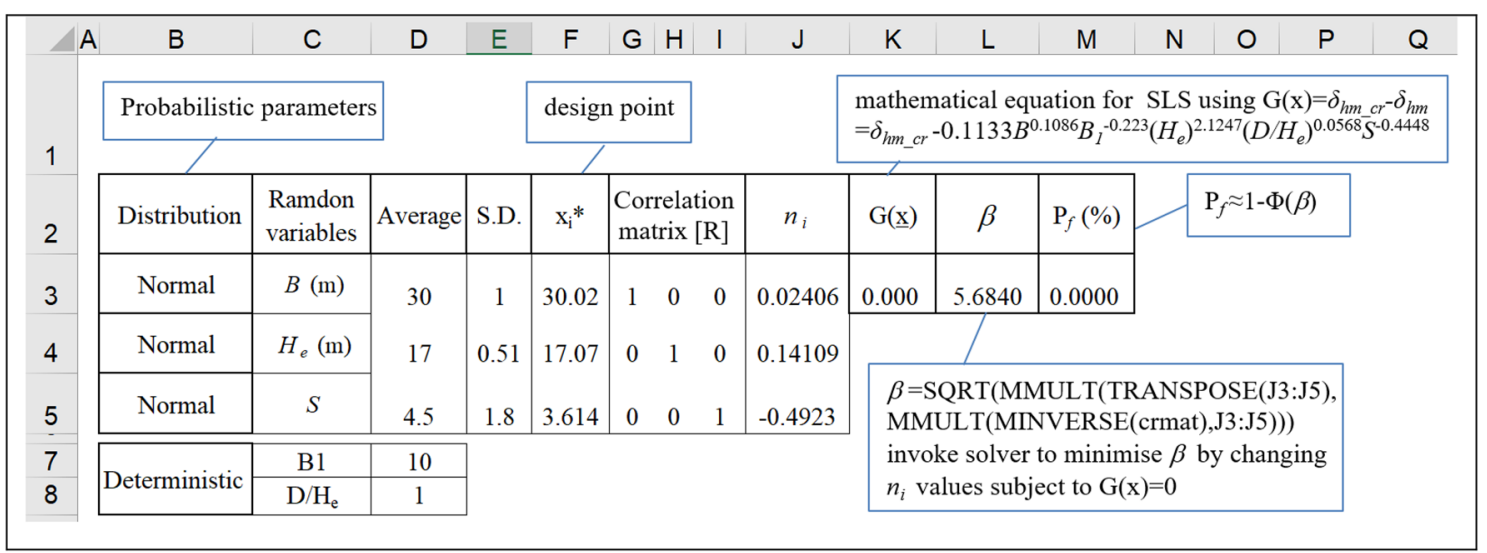

(b) Calculation on $\beta$ and $P_{f}$ for serviceability limit state using FORM spreadsheet

Fig. 9 a Calculation on $\beta$ and $P_{f}$ for the ultimate limit state using FORM spreadsheet. b Calculation on $\beta$ and $P_{f}$ for serviceability limit state using FORM spreadsheet

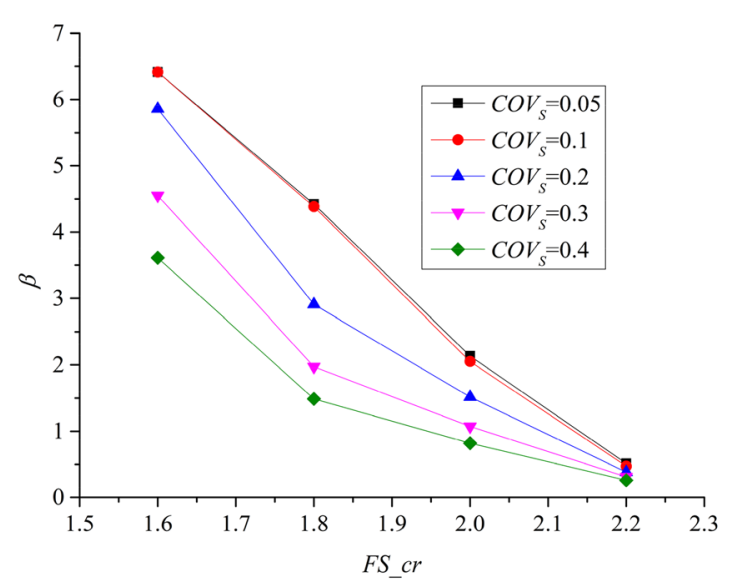

(a)

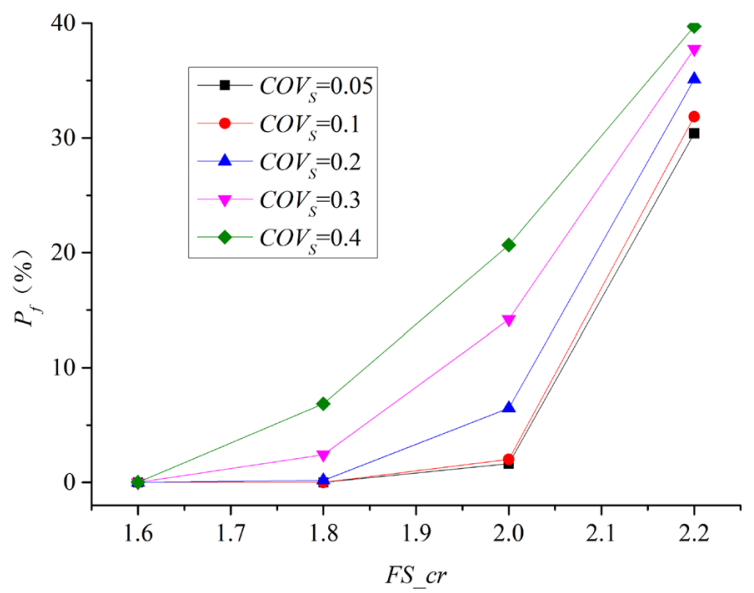

(b)

Fig. 10 Influence of $C_{S} O V_{S}$ and $F S_{-}$cr on $\mathbf{a} \beta$ and $\mathbf{b} P_{f}$ for $B_{1}=5 \mathrm{~m}, B=30 \mathrm{~m}, H_{e}=17 \mathrm{~m}, S=4.5 \mathrm{~d}$ 


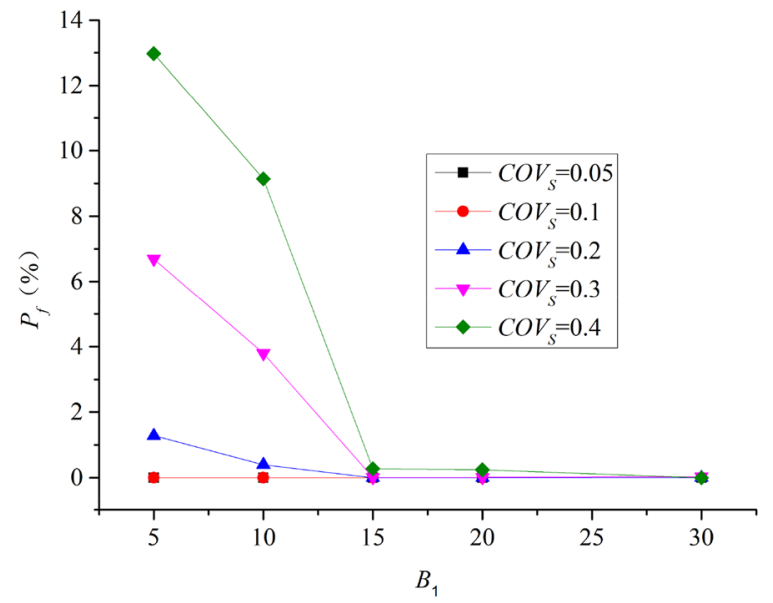

(a) $B=20 \mathrm{~m}$

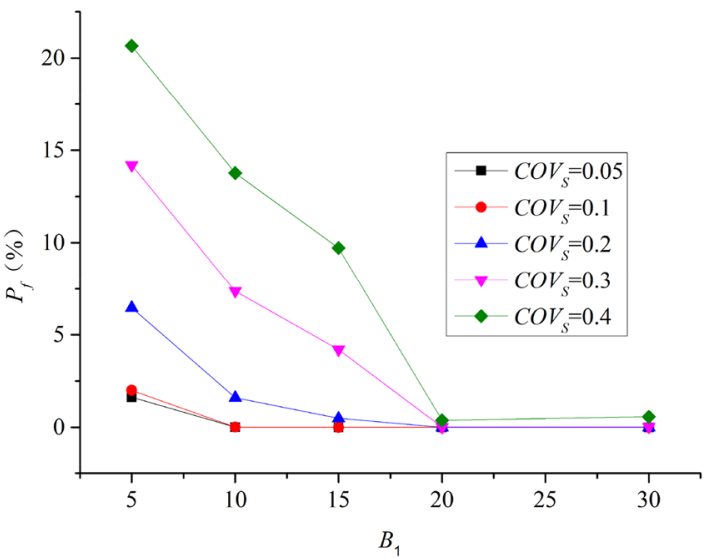

(b) $B=30 \mathrm{~m}$

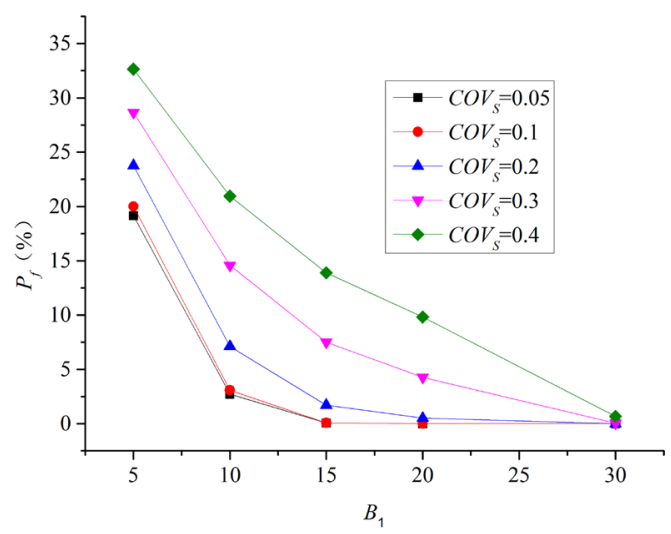

(c) $\mathrm{B}=40 \mathrm{~m}$

Fig. 11 Influence of $\mathrm{COV}_{S}$ and $B_{1}$ on $\beta$ and $P_{f}$ for $B=20,30,40 \mathrm{~m}, H_{e}=17 \mathrm{~m}, S=4.5, F S \_c r=2.0$

$B=20 \mathrm{~m}, B_{1}=20 \mathrm{~m}$ when $B=30 \mathrm{~m}, B_{1}=30 \mathrm{~m}$ when $B=40 \mathrm{~m}$. It suggests that $\operatorname{COV}_{S}$ has little influence on $P_{f}$ when $B_{1} \geq 15$ when $B=20 \mathrm{~m}, B_{1} \geq 20 \mathrm{~m}$ when $B=30 \mathrm{~m}, B_{1} \geq 30 \mathrm{~m}$ when $B=40 \mathrm{~m}$.

\subsection{Probabilistic assessment of the serviceability limit state}

In this section, the serviceability limit state of the braced excavation-upper slope system is considered. Figure 12 plots the influence of $\mathrm{COV}_{S}$ and the threshold max. wall deflection $\delta_{h m_{c} c r}$ on $\beta$ and $P_{f}$ for $B=30 \mathrm{~m}, H_{e}=17 \mathrm{~m}, S=4.5$ and $B_{1}=20,20,40 \mathrm{~m}$, respectively. The results indicate that both $\mathrm{COV}_{s}$ and $\delta_{h m_{-} c r}$ significantly influence the $\beta$ and $P_{f}$ values. However, the influence of $\mathrm{COV}_{S}$ on $\beta$ and $P_{f}$ is not as significant as that of $\delta_{h m_{-} \text {cr }}$ especially when $\mathrm{COV}_{S}$ is greater than 0.20 .

Figure 13 shows the influence of $\mathrm{COV}_{S}$ on $\beta$ for $\mathrm{H}_{e}=17 \mathrm{~m}$, $S=4.5, \delta_{h m_{-} c r}=23 \mathrm{~mm}, B=20,30,40 \mathrm{~m}$ and $B_{1}=10,15 \mathrm{~m}$ respectively. It is clear that $\beta$ decreases exponentially as the $\mathrm{COV}_{s}$ become greater. It is logical that $\beta$ increases when the excavation is further away from the slope.

\subsection{System reliability analysis}

In the assessment of deep braced excavations adjacent to slopes, it is logical to consider the interaction between the global ULS factor of safety and the SLS of the wall deflections together rather than independently. Therefore, it requires a system reliability analysis approach that can consider each limit state and the interaction between the various limit states $[17,20,27,29]$. The proposed system reliability is ensured in this study by performing probabilistic analysis on the global factor of safety and at the same time satisfying the criterion that the threshold maximum wall deflection should not be exceeded. As shown in Fig. 14, The regression model predicting the maximum lateral wall deflection $\delta_{h m}$ is implemented into Cell K8 representing the constraint from SLS, in which mathematical expression of $\delta_{h m-c r}-\delta_{h m} \geq 0$ must be satisfied for each 


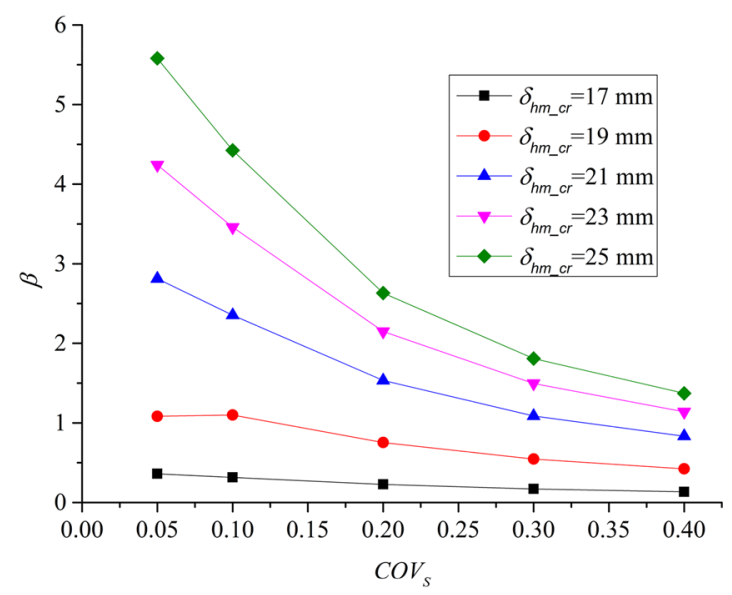

(a) $B_{1}=20 \mathrm{~m}$

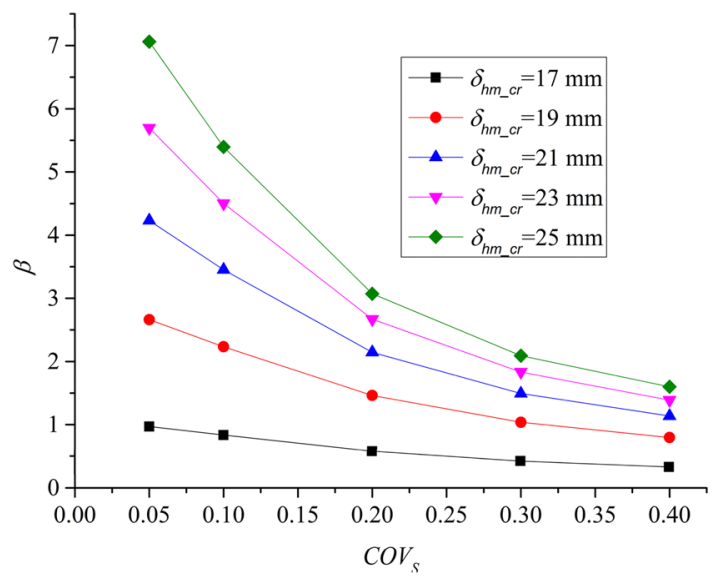

(b) $B_{1}=30 \mathrm{~m}$

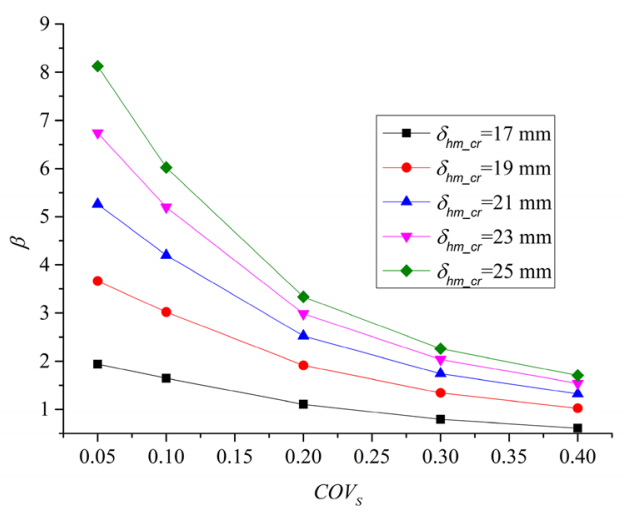

(c) $B_{1}=40 \mathrm{~m}$

Fig. 12 Influence of $\mathrm{COV}_{S}$ and $\delta_{h m_{-} c r}$ on $\beta$ for $B=30 \mathrm{~m}, H_{e}=17 \mathrm{~m}, S=4.5, B_{1}=20,20,40 \mathrm{~m}$

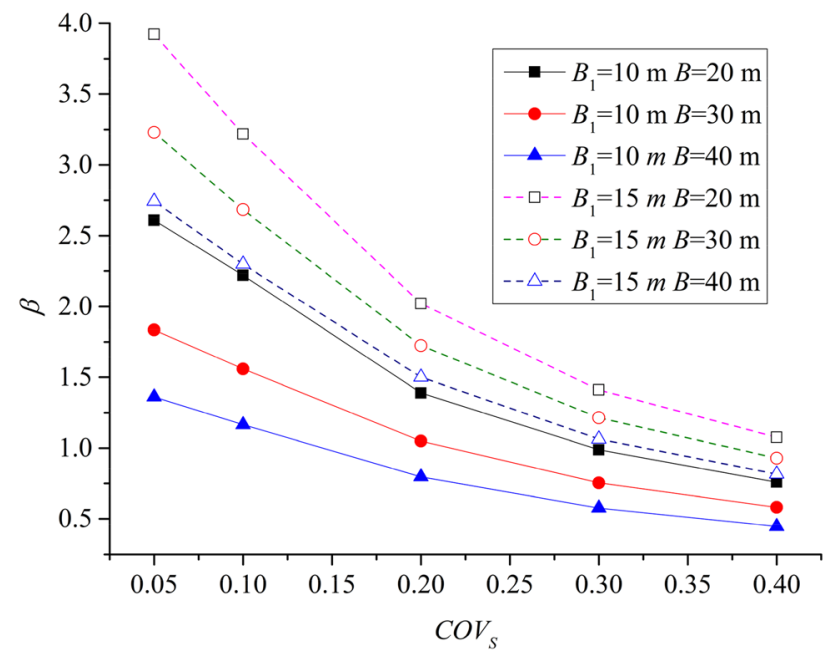

Fig. 13 Influence of $\mathrm{COV}_{S}$ on $\beta$ for $H_{e}=17 \mathrm{~m}, S=4.5, \delta_{h m_{-} c r}=23 \mathrm{~mm}$, $B=20,30,40 \mathrm{~m}$ and $B_{1}=10,15 \mathrm{~m}$ combination of parameters $B, H_{e}$ and $S$. Though this way, the parameter combinations for derived design point satisfy both the ULS and SLS simultaneously and the system reliability is ensured.

Figure 15 plots the system reliability analysis results for configurations with different $B_{1}$ values and penetration depths for the case with $B=\mathrm{N}(30,3), H_{e}=\mathrm{N}(20,0.6)$, $\ln (S)=\mathrm{N}(4.5,0.45), F S_{c r}=1.5$ and $\delta_{h m}=30 \mathrm{~mm}$, where $\mathrm{N}(\mathrm{a}, \mathrm{b})$ represents the normal distribution with mean value of $a$ and standard deviation of $b$. It is obvious that as $B_{1}$ increases, the $\beta$ value increases. The influences of penetration depth $D /$ He on $\beta$ and $P_{f}$ are not as significant as $B_{1}$.

Figure 16 shows the influence of the chosen threshold factor of safety FS_cr on the system reliability when the threshold maximum wall deflection is set at $30 \mathrm{~mm}$. It is should be noted that $\beta$ decreases linearly with the FS_cr with different $B_{1}$ while $P_{f}$ increases exponentially as the $F S_{-c r}$ becomes greater. 


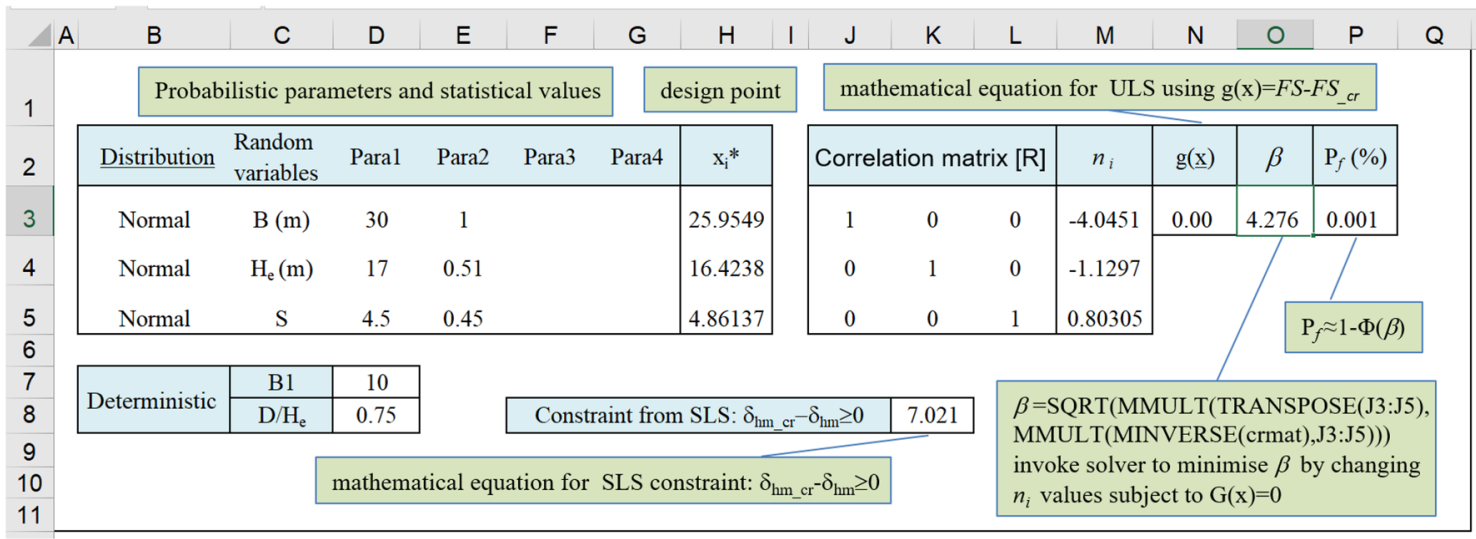

Fig. 14 Calculation on $\beta$ and $P_{f}$ for system reliability using FORM spreadsheet
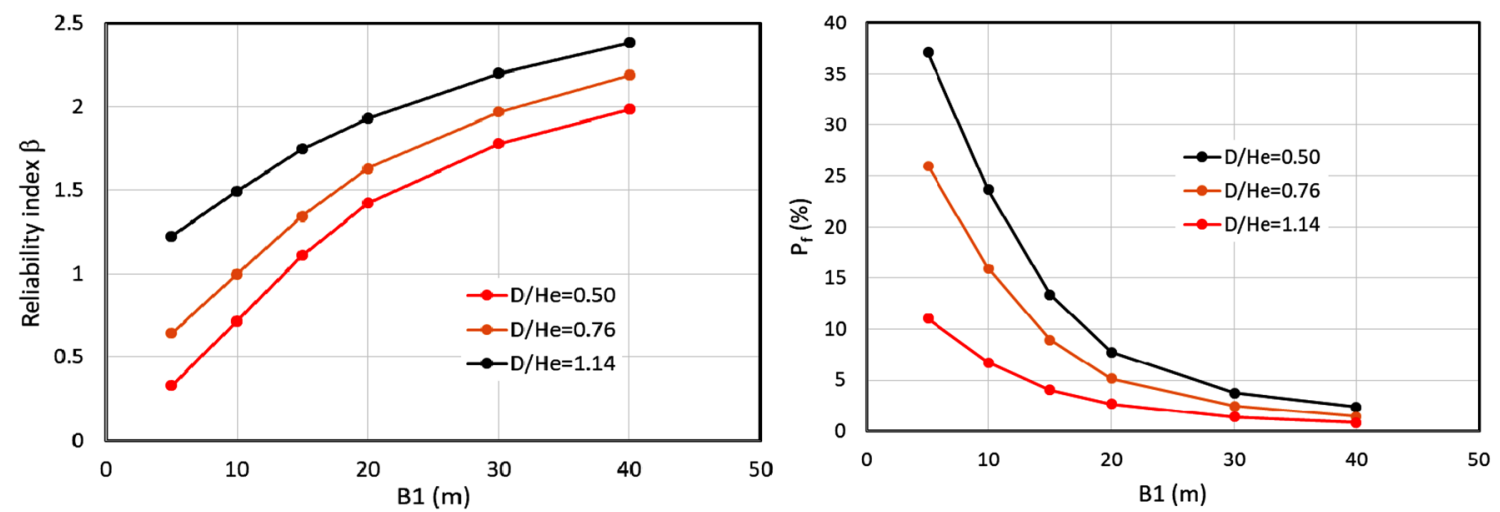

Fig. 15 System reliability analysis results for different excavation configurations
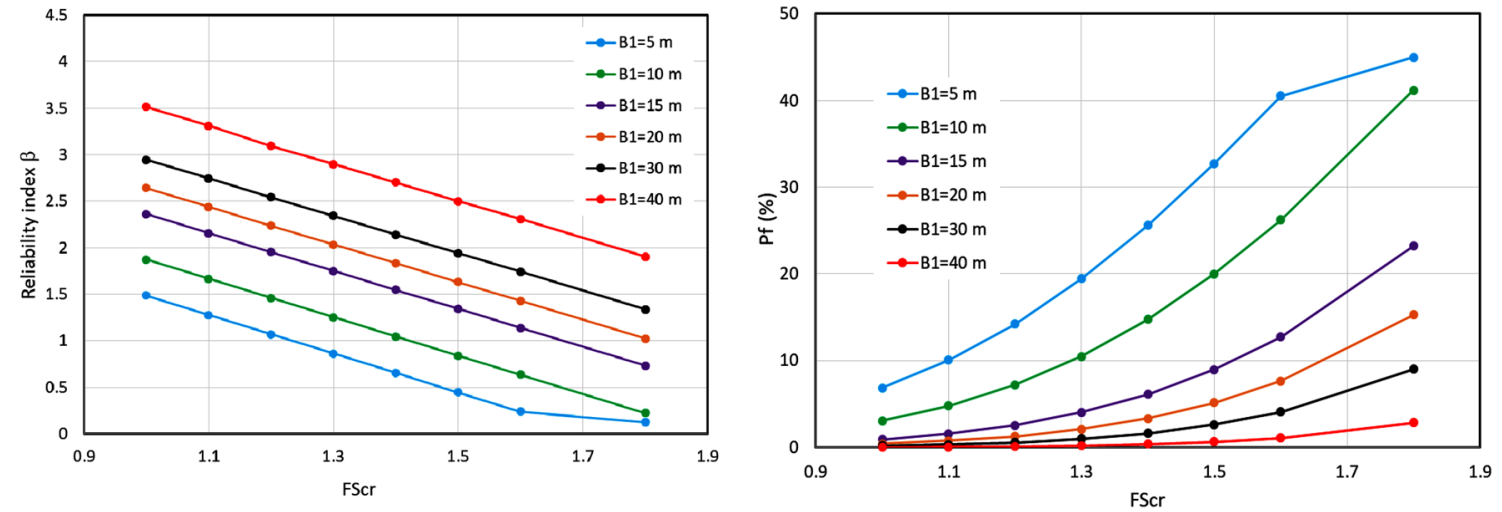

Fig. 16 Influence of threshold FS on system reliability

Figure 17 illustrates the influence of the chosen threshold $\delta_{h m_{-} c r}$ on the system reliability when the threshold $F S_{c r}$ is set at 1.5. It is obvious that the greater the threshold $\delta_{h m_{\_} c r}$ value is set, the greater the reliability index $\beta$ derived, which indicating a much smaller possibility that the actual $\delta_{h m_{c} c r}$ is exceeded. It also can be observed that the $P_{f}$ decreases with $\delta_{h m_{-} c r}$ and converged at $\delta_{\text {hm_cr }}=40 \mathrm{~mm}$. 

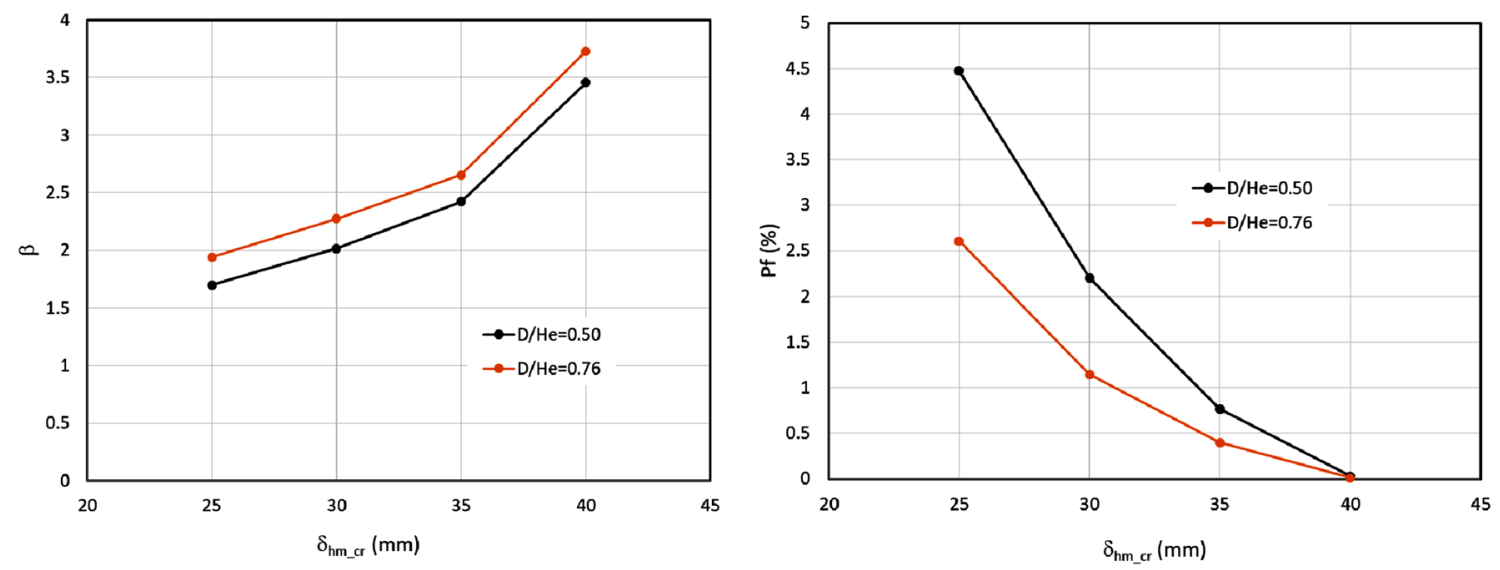

Fig. 17 Influence of threshold $\delta_{h m}$ on system reliability

\section{Summary and conclusions}

This paper presents numerical investigations on the performance of a braced excavation adjacent to an existing slope, from the perspectives of the global factor of safety and the maximum lateral wall deflections. It also proposed a probabilistic framework for the quantitative assessment of both the ultimate and the serviceability limit states in view of some design and construction uncertainties. The main conclusions arrived at include:

(1) Based on the case study, excavations close to an existing slope may result in a significant reduction of the global FS from 2.341 to 1.705 for the braced excavation- upper slope system. The amount of reduction is closely associated with the excavation depths and widths, the penetration depth and the distance between the excavation and the slope toe.

(2) The wall deflections are also significantly influenced by the key factors listed in conclusion point (1).

(3) Surrogate models for ULS and SLS are developed and implemented into FORM for reliability analysis.

(4) The proposed system reliability can be assessed by performing a probabilistic analysis on the global factor of safety while setting the threshold maximum wall deflection as a constraint for optimization.

It should be noted that the proposed probabilistic framework is based on an actual case study in Chongqing as illustrated in Fig. 2 in which the slope angle and soil properties are deterministic and fixed. The effects of the inherent variability of the soil properties and the slope angle on the braced excavation-upper slope system performance will be considered in a future study.

Funding This study was funded by Natural Science Foundation of Chongqing, China (cstc2018jcyjAX0632), Venture \& Innovation Support Program for Chongqing Overseas Returnees (cx2017123), as well as Chongqing Engineering Research Center of Disaster Prevention \& Control for Banks and Structures in Three Gorges Reservoir Area (Nos. SXAPGC18ZD01 and SXAPGC18YB01).

\section{Compliance with ethical standards}

Conflict of interest The authors declare that they have no conflict of interest.

\section{References}

1. Brinkgreve RBJ, Kumarswamy S, Swolfs WM (2017) Plaxis 2D 2017 user's manual. Plaxis bv, Delft

2. Brinkgreve RBJ, Bakker HL (1991) Non-linear finite element analysis of safety factors. In: Proceedings of 7 th international conference on computer methods and advances in geomechanics, 23, pp 1117-1122

3. Chen FY, Wang L, Zhang WG (2019) Reliability assessment on stability of tunneling perpendicularly beneath an existing tunnel considering spatial variabilities of rock mass properties. Tunn Undergr Space Technol 88:276-289

4. Cheng YM, Lansivaara T, Wei WB (2007) Two-dimensional slope stability analysis by limit equilibrium and strength reduction methods. Comput Geotech 34(3):137-150

5. Dyson AP, Tolooiyan A (2018) Optimisation of strength reduction finite element method codes for slope stability analysis. Innov Infrastruct Solut 3:38. https://doi.org/10.1007/s4106 2-018-0148-1

6. Gao X, Liu HL, Zhang WG, Wang W, Wang ZY (2019) Influences of reservoir water level drawdown on slope stability and reliability analysis. Georisk 13(2):145-153

7. Goh ATC, Fan Zhang, Zhang WG*, Zhang YM, Liu H (2017) A simple estimation model for 3D braced excavation wall deflection. Comput Geotech 83:106-113 
8. Goh ATC, Zhang RH, Wang W, Wang L, Liu H, Zhang WG (2019) Numerical study of the effects of groundwater drawdown on ground settlement for excavation in residual soils. Acta Geotech. https://doi.org/10.1007/s11440-019-00843-5

9. Goh ATC, Zhang WG (2012) Reliability assessment of stability of underground rock caverns. Int J Rock Mech Min Sci $55: 157-163$

10. Goh ATC, Zhang WG, Wong KS (2019) Deterministic and reliability analysis of basal heave stability for excavation in spatial variable soils. Comput Geotech 108:152-160

11. Hasofer AM, Lind N (1974) An exact and invariant first-order reliability format. J Eng Mech 100:111-121

12. Ishii Y, Ota K, Kuraoka S, Tsunaki R (2012) Evaluation of slope stability by finite element method using observed displacement of landslide. Landslides 9(3):335-348

13. Itasca Consulting Group (2002) FLAC3D manual

14. Ji J, Zhang CS, Gao YF, Kodikara J (2019) Reliability-based design for geotechnical engineering: an inverse FORM approach for practice. Comput Geotech 111:22-29

15. Li YH, Liu P, Liu JQ, Han XF (2011) Stability and safety analysis of braced excavation for subway station during construction under the condition of side slope. Appl Mech Mater 99-100:1166-1170

16. Lian ZY, Han GC, Kong XJ (2001) Stability analysis of excavation by strength reduction FEM. Chin J Geotech Eng 23(4):5

17. Liu H, Low BK (2017) System reliability analysis of tunnels reinforced by rock bolts. Tunn Undergr Space Technol 65:155-166

18. Low BK, Tang WH (2007) Efficient spreadsheet algorithm for firstorder reliability method. J Eng Mech ASCE 133(12):1378-1387

19. Luo $P(2013)$ The soil stability analysis of soft soil slope toe excavation. Master Thesis, Hefei University of Technology, Hefei, China (in Chinese)

20. Lü Q, Chan CL, Low BK (2013) System reliability assessment for a rock tunnel with multiple failure modes. Rock Mech Rock Eng 46:821-833

21. Oberhollenzer S, Tschuchnigg F, Schweiger H (2018) Finite element analyses of slope stability problems using non-associated plasticity. J Rock Mech Geotech Eng 10:1091-1101

22. Poh TY, Wong IH, Chandrasekaran B (1997) Performance of two propped diaphragm walls in stiff residual soils. J Perform Constr Facil 11(4):190-199

23. Schneider-Muntau B, Medicus G, Fellin W (2018) Strength reduction method in Barodesy. Comput Geotech 95:57-67

24. Tschuchnigg F, Schweiger HF, Sloan SW (2015) Slope stability analysis by means of finite element limit analysis and finite element strength reduction techniques. Part II: back analyses of a case history. Comput Geotech 70:178-189

25. Varzaghani MI, Ghanbari A (2014) A new analytical model to determine dynamic displacement of foundations adjacent to slope. Geomech Eng 6:561-575
26. Wang QY, Gu DP, Zhang JS, Xiong ZB (2011) Analysis of slip-risk and dynamic monitoring of a high building slope fringed a deep foundation pit. J Saf Environ. 11(2):6 (in Chinese)

27. Zeng P, Senent S, Jimenez R (2014) Reliability analysis of circular tunnel face stability obeying hoek-brown failure criterion considering different distribution types and correlation structures. J Comput Civ Eng 30:2390-2398

28. Zhang RH, Zhang WG, Goh ATC (2018) Numerical investigation of pile responses caused by adjacent braced excavation in soft clays. Int J Geotech Eng. https://doi.org/10.1080/19386 362.2018.1515810

29. Zhang WG, Goh ATC (2012) Reliability assessment on ultimate and serviceability limit states and determination of critical factor of safety for underground rock caverns. Tunn Undergr Space Technol 32:221-230

30. Zhang WG, Goh ATC (2015) Regression models for estimating ultimate and serviceability limit states of underground rock caverns. Eng Geol 188:68-76

31. Zhang WG, Goh ATC (2016) Multivariate adaptive regression splines and neural network models for prediction of pile drivability. Geosci Front 7:45-52

32. Zhang WG, Wang W, Zhou D, Goh ATC, Zhang RH (2018) Influence of groundwater drawdown on excavation responses-a case history in Bukit Timah granitic residual soils. J Rock Mech Geotech Eng 10:856-864

33. Zhou A, Li C, Jiang P, Yao K, Li N, Wang W (2018) Slip line theory based stability analysis on the influence of deep excavation on adjacent slope. Math Probl Eng. https://doi. org/10.1155/2018/2041712

34. Zhou W, Gong C, Hong HP (2017) New perspective on application of first-order reliability method for estimating system reliability. J Eng Mech 143(9):04017074

35. Zienkiewicz OC, Humpheson C, Lewis RW (2015) Associated and non-associated visco-plasticity and plasticity in soil mechanics. Geotechnique 25(25):671-689

36. Zou HF, Liu SY, Cai GJ, Bheemasetti TV, Puppala AJ (2017) Mapping probability of liquefaction using geostatistics and first order reliability method based on CPTU measurements. Eng Geol 218:197-212

Publisher's Note Springer Nature remains neutral with regard to jurisdictional claims in published maps and institutional affiliations. 